This paper is published in the open archive of Mid Sweden University

DIVA http://miun.diva-portal.org

with permission of the publisher

Citation for the peer-reviewed published paper:

Gorski D, Hill J, Engstrand P, Johansson L. Review: Reduction of energy consumption in TMP refining through mechanical pre-treatment of wood chips. Nordic Pulp \& Paper Research Journal. 2010;25(2):156-161.

URL to article at publishers site:

http://dx.doi.org/10.3183/NPPRJ-2010-25-02-p156-161 


\title{
Review: Reduction of energy consumption in TMP refining through mechanical pre-treatment of wood chips
}

\author{
Dmitri Gorski, Jan Hill, Per Engstrand, and Lars Johansson
}

KEYWORDS: TMP refining, Chip pre-compression, Chip pre-treatment, Energy reduction, ATMP

SUMMARY: This review covers the effect of mechanical pre-treatment of wood chips on the energy consumption in refining and the quality of pulp. To understand the mechanisms of mechanical pre-treatment, a short description of relevant refining theory and reported effects of pre-treatment on wood morphology is given. Mechanical pre-treatment offers a chance to utilize the energy needed to defibrate chips in a more efficient way, minimizing the cyclic elastic deformations which are the main defibration mechanism in refining. Studies of fibre morphology indicate that compressive pretreatment mechanically introduces favorable weak points in the S1 and S2 fibre walls where defibration proceeds easier upon subsequent refining.

Published results which cover the effect of the pretreatment on energy consumption and pulp properties are reviewed. Energy reduction of between $10 \%$ and $30 \%$ is reported in the literature. High ratio of volumetric compression is necessary. Pressurized conditions are required to ensure that the fibres are not damaged during the pre-treatment. Other effects of compressive pretreatment include a more uniform chip size and moisture content, better penetration of chemicals and removal of extractives from the chips. A list of equipment used for chip pre-compression is provided together with published results of pilot-scale and mill-scale operation.

\footnotetext{
ADDRESSES OF THE AUTHORS: Dmitri Gorski (dmitri.gorski@norskeskog.com) and Jan Hill (jan.hill@norskeskog.com): Norske Skog Focus AS, N1756, Halden, Norway. Per Engstrand (per.engstrand@miun.se): Mid Sweden University, FSCN, 851 70, Sundsvall, Sweden. Lars Johansson (lars.johansson@pfi.no): PFI AS, Høgskoleringen 6b, NO-7491, Trondheim, Norway.

Corresponding author: Dmitri Gorski
}

Refining of thermomechanical pulp is a very energy-intensive process. Mechanical pre-treatment of wood chips prior to refining has been shown to reduce total energy consumption, facilitate removal of extractives, have positive synergies with chemical and enzymatic pre-treatments and improve impregnation of chips. There are a number of publications dealing with different aspects of mechanical pre-treatment but few of them give a comprehensive overview of what has been done in this field.

Pre-compression of wood blocks prior to refining was first experimented with more than 25 years ago (Frazier and Williams 1982). A substantial energy reduction was achieved and a number of papers dealing with different aspects of compressive pretreatment have been published since then.

Devices for chip pre-compression have been used in pilot and full scale for a long time (Allan et al. 1968; Thornton and Nunn 1978; de Choudens et al. 1985). Unfortunately, compressive pre-treatment has often resulted in fibre damage (Sabourin 1998). When increased compression ratio was combined with pressurized high-temperature conditions in precompression equipment the laboratory and pilot scale results became more successful (Sabourin 2000; Sabourin 2003; Sabourin et al. 2002). Also, this kind of equipment has been traditionally used to achieve chip impregnation, mainly in the CTMP process, and the focus was not on optimizing the effects of mechanical pre-treatment.

This review summarizes the results of research on mechanical chip pre-treatment carried out during the last three decades. The areas covered are morphological aspects of pre-treatment, its effect on overall electrical energy consumption and product quality as well as its development into industrial scale applications.

\section{Mechanics of TMP refining}

The three major objectives of mechanical pulping are (Attack 1981):

- $\quad$ to reduce wood to its constituent fibres

- $\quad$ to retain the integrity of a considerable fraction of those fibres

- $\quad$ to induce a maximum amount of flexibility and fibrillation into the separated fibres and fine fibre fragments

The first objective is referred to as defibration. The third objective is fibre development (internal and external). The second objective is a prerogative for a successful TMP manufacture and also explains the fundamental difference between the first and the third objective. During defibration the goal is to split chips into individual fibres as effectively as possible. Large plastic deformations to the chips are 
desired and induced. During fibre development, on the other hand, a large plastic deformation often means that fibres are damaged by cutting them (Koran 1980). A better way to develop a fibre is to carefully induce small plastic and elastic deformations in a cyclic process called fatigue (Salmén et al. 1985; 1997). Fatigue is the main mechanism of refining (Hartler 1980) used today both for defibration and fibre development. However, fatigue is obviously not the most effective way to induce large plastic deformations - a lot of energy is converted to heat in cyclic fashion. It would therefore be theoretically possible to achieve defibration in a more effective process than refining, via a process that would utilize a lower number of stressing cycles (thereby avoiding energy loss as heat) and higher stress amplitude to induce permanent plastic deformations.

\section{Effect of compressive pre-treatment on wood and fibre morphology}

Effects of compressive pre-treatment on wood and fibre morphology were first described by Frazier and Williams in their study of axial pre-compression of western hemlock blocks (Frazier and Williams 1982). Separation at S1 or S2 fibre walls resulting from the pre-compression is thought to explain the better pulp properties observed. If the fibres are more separated from one another already at the refiner inlet, more of the refiner energy can be directed to developing fibre properties instead of separating the fibres in a less efficient way.

Axial compression leads to shearing of S1, P and middle lamellae between the S2 layers of adjacent cell walls (Booker and Sell 1998). Upon the shearing action, fibre wall delamination should occur at the weakest point, which depends on fibril angle, lignin content, fibre wall thickness and ambient conditions.

Heikkurinen et al. investigated the effect of initial defibration on the properties of refiner mechanical pulp made from Norway spruce (Heikkurinen et al. 1993). The fibre separation step is concluded to be crucial in determining how efficiently the energy is applied in subsequent refining stages. This conclusion seems logical, since once the fibres are separated the applied energy is directed to developing fibre properties. If the fibre separation step is inefficient, the applied energy will be used up in trying to complete the fibre separation work and fibre development will be less effective. According to many investigations, fibre separation is initiated in a pre-compression stage (Frazier and Williams 1982; Sabourin 1998; Kure et al. 1999; Robertsen 2001). If this is true, the pre-compression stage is crucial in determining total refining energy.
It should also be noted that radial pre-compression of chips seems to be less effective in achieving fibre separation than axial pre-compression. This is probably due to the fact that thin-walled earlywood fibres are the weakest link in a chip subjected to radial compression (Hickey and Rudie 1993; Salmén et al. 1997), while during axial compression the load is distributed more uniformly between the earlywood and latewood.

Earlywood and latewood behave very differently upon compression. During axial compression, latewood fibres are separated to a much larger extent than earlywood fibres. Earlywood fibres show signs of much more cell wall damage than latewood fibres (de Choudens 1985; Law et al. 2006). Shives consist mostly of earlywood fibres (Remé and Helle 2000). During radial compression, most of the energy is absorbed in the earlywood sections while latewood sections remain unchanged (Peng and Granfeldt 1996).

\section{Effect of compressive pre-treatment on energy consumption}

The first report of a reduction in refining energy consumption using axially pre-compressed western hemlock blocks describes a reduction of $9 \%$ for TMP and 40\% for CTMP (Frazier and Williams 1982).

Thornton and Nunn at Beloit Corporation replaced a conveyor belt feeder to a pressurised primary refiner with a plug screw feeder with a 2.7:1 compression ratio (Thornton and Nunn 1978). This gives a significant energy reduction in refining.

Several reports concerning commercial use of the $\mathrm{BiVis}$ extruder were published by de Choudens and Anglier in late 1980's, a description of this technology is given later in this review. Although the focus was on quality improvement, energy reduction due to pre-treatment is reported as well.

Energy reduction by about $23 \%$ for spruce compared to the standard TMP has been reported (de Choudens and Anglier 1987; de Choudens et al 1989). Kurdin and Tantalo report an energy reduction of $30 \%$ for pine using $\mathrm{BiVis}$ extrusion pulping (Kurdin and Tantalo 1987).

A positive effect on energy consumption in refining of Norway spruce after using a so called PREX-treatment involving a compression screw are reported (Peng and Granfeldt 1996; Johansson et al 1999).

A number of studies have been conducted using the Andritz MSD Impressafiner (Kure et al. 1999; Robertsen et al. 2001; Sabourin 1998; Sabourin et al. 2002). Impressafiner treatment is often combined with elevated primary refiner rotational speeds and other process modification leading together to about 
$500 \mathrm{kWh} / \mathrm{t}$ reduction in energy consumption. Robertsen et al. reported on energy reduction after pure Impressafiner pre-treatment - with better effect on pine chips than spruce chips (Robertsen et al. 2001). Sabourin reported on energy reduction of $10 \%$ using compressive pre-treatment of White spruce. Impressafiner equipment is described in detail later in this paper.

A novel process denoted ATMP was presented by Hill et al. (Hill et al. 2009). The key operation in this process is mechanical pre-treatment of wood chips which is suggested to separate defibration of the chips from fibre development. In ATMP, chemical agents are applied between those two stages. Thus, chemically enhanced fibre development can be achieved without the negative effects chemical agents have on defibration which would otherwise become more CTMP-like. ATMP is shown to produce pulp with the same or better properties than pulp produced by a conventional TMP process at $20 \%$ lower energy consumption in commercial scale using addition of bisulphite.

There seems to be no doubt that compressive pretreatment leads to a reduction in energy consumption for the overall refining process by allowing for lower energy input in subsequent refining stages. There now exist commercially available solutions for compressive chip pretreatment and they offer opportunities for new design and further optimization of the refining processes.

\section{Other effects of compressive pre-treatment}

Sabourin states that it is possible to achieve further energy reduction with a combination of mechanical pre-treatment and addition of chemicals to the pulping process (Sabourin 1998). Pre-treatment equipment opens up the wood structure very effectively and facilitates the penetration of chemicals. This is confirmed in pilot trials and commercial scale (Hill et al. 2009).

In order for the chemicals to be evenly absorbed into the chips, the moisture content of the wood has to be even throughout and in between the particles. Differences in moisture content between chips lead to differences in how much the chemicals penetrating them are diluted. Since the chemical passage into the chips is obstructed by air pockets, it is important to remove them from the chips prior to chemical addition. Efficient and well-established way to remove air and liquid from the chips is steaming and compression followed by cold liquid impregnation (Barbe et al. 1993; Johansson et al. 1999).

Uniform moisture content in the chips gives a more uniform pulp. Thus, uniform impregnation achieved in compressive pre-treatment affects the pulp quality (Peng and Granfeldt 1996). Pre-compression of chips also leads to improved mass transfer of chemicals (de Choudens et al. 1985). An additional positive effect is that a more even chip size distribution is achieved in a compressive pretreatment (Kurdin and Tantalo 1987). The chips are homogenized, smoothing out density variations and moisture content (Johansson et al. 1999). Uneven chip size causes pressure and load variations in the refiner leading to an unstable process and adversely effecting pulp quality (Sabourin et al. 2002).

Compressive pre-treatment of wood chips is an effective way of removing extractives; up to $40 \%$ could be removed in compressive pre-treatment of pine in an RT Impressafiner (Tanase et al. 2009). During pre-treatment of spruce, up to $10 \%$ could be removed. Extractives are known to interfere with refining and possibly have a negative impact on energy consumption and pulp quality (Svensson 2008; Engstrand et al. 1995).

\section{Industrial chip pre-compression techniques}

Corson states that the refining process today is essentially the same as first described by Gottlieb Keller in 1840 's, the process has not been fundamentally altered during the past 150 years (Corson 2001). According to him, the opportunity for a quantum change lies within the fibre itself rather than in new machinery. This is of course correct from the point of view that a fundamentally new process can only be achieved through perfection of understanding of refining mechanisms. But once the understanding is in place, new machinery has to be developed to be able to achieve the desired process.

During the last 20 years there have been a number of devices on the market which can claim to be equipment for compressive mechanical pretreatment. However, many of them have been unsuccessful in achieving energy reduction due to low compression ratio, temperature and pressure.

\section{Plug screw feeder}

Thornton and Nunn replaced a traditional conveyer belt with a pressurized plug screw feeder (Fig l) at the inlet of a pressurized first stage refiner in a TMP pilot plant at Pittsfield, USA (Thornton and Nunn 1978). This gave a higher degree of extractives removal and energy reduction by $70 \mathrm{kWh} / \mathrm{BDT}$ for Loblolly pine raw material and $100 \mathrm{kWh} / \mathrm{BDT}$ for White spruce raw material. The plug screw feeder had atmospheric inlet and pressurized discharge with an overall compression ratio of 2.7 and 
atmospheric pre-steaming. Examination of photomicrographs of chips pre-compressed in the plug screw feeder revealed a high degree of fibre separation, mostly in the middle lamellae. Compressive pre-treatment was stated to lead to shifting of the cell wall resulting in higher stretch of the pulp fibres.

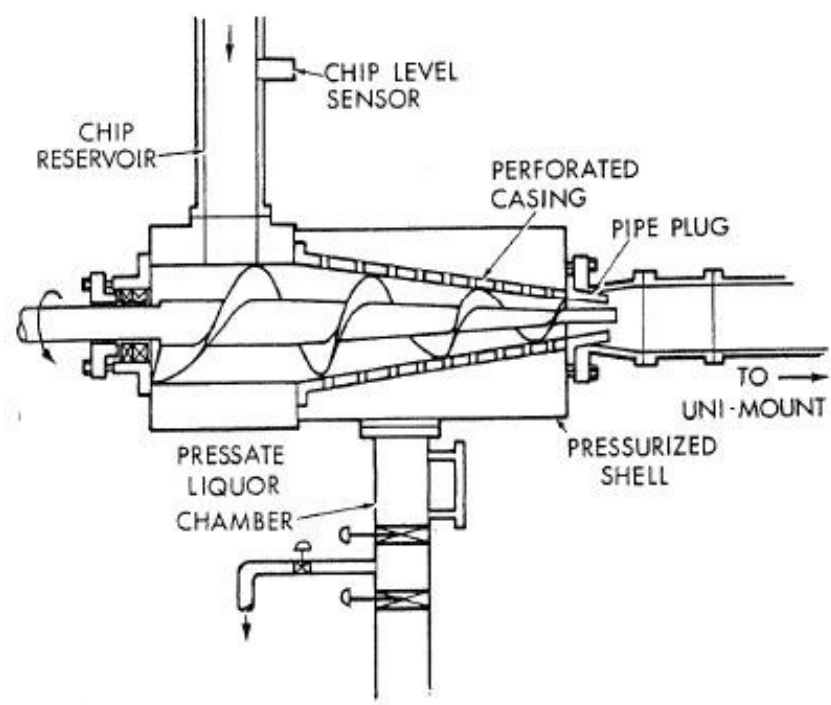

Fig 1. Plug screw feeder (Thornton and Nunn 1978).

\section{Bi-Vis Extruder}

In the early 80's CTP and the Clextral and Autochem companies in France developed a device they called the BiVis Extruder (de Choudens et al. 1985). Defibration of chips and introduction of chemicals into the pulp were two reasons for installing a $\mathrm{BiVis}$ extruder. It was mainly seen as a reactor where different chemicals were introduced rather than as a means for mechanical pre-treatment of chips. However, better kinetics of the reactions is reported suggesting an easier passage of chemicals into the chip structure which is opened up by the defibrating pre-treatment.

Energy reduction in subsequent pulping is reported both for spruce and pine. It is, however, difficult to say how much of the reduction is due to chips macerating and how much comes from sulphonation of the chips in the extruder. Energy reduction during production of spruce is reported to be larger than is the case with pine. Energy reduction by $35 \%$ for spruce and $23 \%$ for pine compared to TMP is reported for pulp treated in a BiVis extruder (de Choudens et al. 1985; 1987; 1989).

Bi-Vis extruders have never become common in TMP mills, possibly due to their comparatively small size, complexity and high cost. They are, however, used today in mills producing pulp from non-wood raw material and in the food industry.

\section{PREX impregnator}

PREX impregnation was developed by Swedish company Defibrator as a means of effective introduction of chemicals into the chips. The PREX impregnator is a compression screw with $3: 1$ compression ratio where chips are treated with steam and chemicals.

Treatment in a PREX screw is reported to lead to higher pore volume and pore surface because of the macro cracks and micro-cracks formation (Peng and Granfeldt 1996). The cracks indicate the initiation of the chip defibration process.

Reduction of energy consumption in subsequent refining by as much as $10 \%$ or $250 \mathrm{kWh} / \mathrm{t}$ is reported using this device (Johansson et al. 1999). PREX treated pulp is reported to contain higher amount of fines than the control pulp. This, together with reported lower average fibre length, suggests fibre damage occurring in the PREX screw, probably due to unpressurized operation (too low temperature leading to fibre shattering during compression).

\section{MSD and RT Impressafiner}

Reference to the MSD (Modulate Screw Device) Impressafiner (then produced by Bauer Bros. Co.) pre-treatment is given as early as 1968 (Allan et al. 1968). In 1997, Andritz AG introduced a revised type of compression screw equipment called RT Impressafiner (Fig 2), with higher compression ratio $(5: 1)$ and pressurized conditions (1.5 bar) allowing higher temperature (Sabourin 1998). RT stands for "retention and temperature". The electrical power consumption of a mill scale Impressafiner is approximately $20-40 \mathrm{kWh} / \mathrm{ODT}$.

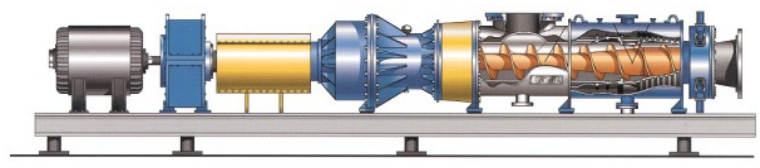

Fig 2. Impressafiner (Andritz AG)

Kure et al. reported an energy reduction of up to $20 \%$ for a process combining compressive pretreatment in an Impressafiner and refining at higher frequency (Kure et al. 1999). Sabourin et al show that newsprint grade pulp can be produced using only $1500 \mathrm{kWh} / \mathrm{t}$ of electrical energy if a process combining mechanical pre-treatment in an Impressafiner with RTS and LC (low-consistency) refining (Sabourin et al. 2002). Sabourin also reported reduction of up to $21-24 \%$ of electrical energy consumption using a combination of mechanical Impressafiner pre-treatment and RTS process (Sabourin 1998). The first commercial scale results from a process incorporating RT pretreatment and targeted addition of chemical agents 
were presented by Hill et al. (2009). Energy reduction of more than $20 \%$ was achieved.

\section{Discussion}

Axial pre-compression seems to defibrate chips (Frazier and Williams 1982; Sabourin 2003; Kure et al. 1999). The effect of radial compression on defibration is not as prominent as axial compression (Dumail and Salmén 1999; de Magistris 2005). A combination of compression and shearing seems to be the most effective way to introduce a permanent deformation in chip and fibre structure (de Magistris 2005; Viforr 2007). Defibration done by traditional methods in a refiner requires a lot more energy than theoretically calculated (van den Akker 1958; Koran 1980). A partial explanation for this is the hysteresis losses in straining the lignin components in rapid cyclic fashion during the defibration phase (Salmén et al. 1985). There are ways of minimizing these losses, yielding a more effective process. Each straining cycle that does not lead to chip defibration carries elastic loss with it - the number of such cycles should therefore be minimized by giving chips fewer but more powerful impacts that lead to faster defibration. The breaker bar section in a traditional refiner may not be the most effective way to achieve this, as the strain rate and the number of impacts are too high, resulting in large number of energy-consuming compression-relaxation cycles. The amplitude of each of the impacts is too low and thus a lot of cycles are needed to break down the chips. A compressive screw seems to be more effective in initially defibrating the chips (Sabourin 2003; Kure et al. 1999). This is due to the magnitude of compression and frequency of compression that is different from a refiner. The shear/compression ratio also seems to be better suited for fibre separation in a compression screw than in a refiner.

\section{Conclusions}

- Defibration and fibre development are two main mechanisms of chip and fibre treatment in mechanical pulp production. They are fundamentally different and should, ideally, be conducted separately (Sabourin 2000). Effective defibration is of high importance for pulp quality throughout the process, particularly in preserving fibre length. Previous publications show that it is possible to achieve a more effective defibration during a compressive pre-treatment (Frazier and Williams 1982; Sabourin 2003; Kure et al. 1999; Robertsen et al. 2001; Law et al. 2006).
Subsequent fibre development is however best conducted in a refiner (Law et al. 2006).

- Compression prior to refining gives a reduction of refining energy by up to $20 \%$ (Sabourin 1998; Kure et al. 1999; Robertsen et al. 2001). This happens probably due to favorable initial fibre separation.

- Mechanical pre-treatments of chips allows for a more effective chemical and enzymatic treatment. This is probably due to opened-up chip structure that leads to better mass transfer of chemicals (de Choudens et al. 1987; Hill et al. 2009; Sabourin et al. 2009). Energy reduction by up to $30 \%$ has been reported.

- Separation of defibration and fibre development processes which is achieved during mechanical pre-treatment of chips is a prerequisite for some novel pulping processes such as ATMP. If defibration and fibre development are conducted separately, chemical agents may be applied in the process to enhance the fibre development. The negative influence on fibre separation is avoided and it proceeds in TMP-like manner ensuring the preserved optical properties of TMP (Hill et al. 2009).

- Earlywood and latewood behave very differently upon compression. During axial compression, latewood fibres are separated to a much larger extent then earlywood fibres. Earlywood fibres show signs of much more damage (de Choudens 1985; Law et al. 2006). Shives consist mostly of earlywood fibres (Remé and Helle 2000).

- Combination of shear and compression seems to give the largest positive effect (Johansson et al. 1999; de Magistris 2005)

- Compressive pre-treatment lowers the extractives content in the chips by up to $40 \%$ (Tanase et al. 2009) and smoothes out variations in density and moisture content (Johansson et al. 1999).

\section{Acknowledgements:}

The review is a part of a Ph.D. project (Dmitri Gorski) that is partly financed by the Research Council of Norway and the Swedish Knowledge Foundation. Without their support and support from Norske Skog and Andritz, this work would not have been possible. Dr. John Richardson is acknowledged for linguistic help.

\section{Literature:}

Van Den Akker J.A. (1958): Fundamentals of papermaking fibres, Tech. Section of British Paper and Board Makers' Association, Cambridge, England, p. 435 
Allan R.S., Skeet C.W. and Forgacs O.L. (1968): Refiner groundwood from deciduous species, Pulp Paper Can., p. 74

Atack D. (1981): Fundamental differences in energy requirement between the mechanical pulping processes, Svensk Papperstidning, 84(14), p. 22

Barbe M.C., Janknecht S. and Sauriol J.F. (1993): The importance of chip impregnation on refiner pulp quality, Int. Mech. Pulp Conf., Oslo, Norway, Technical Association of Norwegian Pulp and Paper Industry, p. 17

Booker R.E. and Sell J. (1998): The nanostructure of the cell wall of softwoods and its functions in the living trees, Holz als Roh- und Wekstoff, 56(1), p. 1

De Choudens C., Lombardo G., Michalowicz G. and Robert A. (1985): Destruction of wood chips in a cylinder press, Paperi Puu, 67(3), p. 108

De Choudens C. and Angelier R. (1987): Improvement of kinetics of the sulphonation and bleaching action in the manufacture of bleached chemomechanical pulps, Int. Symp. Wood and Pulp Chem., Paris, France, p. 37

De Choudens C., Angelier R., Devic M. and Kervennal J. (1989): Chemithermomechanical pulps at high level of brightness obtained by the BiVis process associated with a sulphonation in reducing medium, Int. Mech. Pulp Conf., Helsinki, Finland., Finnish Pulp and Paper Research Institute, p. 226

Dumail J-F. and Salmén L. (1997): Shear and compression behaviour of wood in relation to mechanical pulping, Int. Mech. Pulp Conf., Stockholm, Sweden, SPCl, p. 213

Engstrand P., Karlström A. and Nilsson L. (1995): The impact of chemical addition on refining parameters, Int. Mech. Pulp Conf., Ottawa, Canada, CPPA, p. 281

Fernando D. and Daniel G. (2008): Exploring Scots pine fibre development mechanisms during TMP processing: Impact of cell wall ultrastructure (morphological and topochemical) on negative behavior, Holzforschung, Vol. 62, p. 597

Frazier W.C. and Williams G.J. (1982): Reduction of specific energy in mechanical pulping by axial pre-compression of wood, Pulp Paper Can., 83(6), p. 87

Hartler N. (1980): How energy can be reduced in refiner mechanical pulping, Pulp Paper Can., 81(6), p. 119

Heikkurinen A., Vaarasalo J. and Karin A. (1993): Effect of initial defiberization on the properties of refiner mechanical pulp, J. Pulp Paper Sci., 19(3), p. 119

Hickey K.L. and Rudie A.W. (1993): Preferential energy absorption by earlywood in cyclic compression of loblolly pine, Int. Mech. Pulp Conf., Oslo, Norway, Technical Association of Norwegian Pulp and Paper Industry, p. 81

Hill J., Johansson L., Sabourin M. and Aichinger J. (2009): Enhancing fibre development at reduced energy consumption using TMP sub-process and targeted chemical application - pilot and commercial scale results, Int. Mech. Pulp Conf., Sundsvall, Sweden, SPCI, p. 36

Johansson L., Peng F.F., Simonson R. and Granfeldt T. (1999): The effect of screw press pre-treatment in CTMP pulping process Paperi Puu, 81(8), p. 559

Karnis A. (1994): The mechanism of fibre development in mechanical pulping, J. Pulp Paper Sci., 20(10), p. 280

Koran Z. (1980): Energy consumption in mechanical fibre separation, CPPA $66^{\text {th }}$ annual meeting, Montreal, Canada, CPPA p. 173
Kurdin J.A. and Tantalo L. (1987): Mechanical pulping by extrusion, Int. Mech. Pulp Conf., Vancouver, Canada, CPPA, p. 105

Kure K.-A., Dahlqvist G., Sabourin M.J. and Helle T. (1999): Development of spruce fibre properties by a combination of a pressurized compressive pre-treatment and high energy refining, Int. Mech. Pulp Conf., Houston, USA, TAPPI, p. 427

Law K.N., Kokta B.V. and Mao C. (2006): Compression properties of wood and fibre failures, J. Pulp Paper Sci., 32(4), p. 1

De Magistris F. (2005): Wood fibre deformation in combined shear and compression, Ph.D. thesis, STFI/KTH, Stockholm, Sweden

Peng F. and Granfeldt T. (1996): Changes in the microstructure of spruce wood chips after screw press treatment, J. Pulp Paper Sci, 22(4), p. 140

Remé P.A., Helle T. (2000): Fibre characteristics of shives initiating web rupture, Nord. Pulp Paper Res. J., 15(4), p. 287

Robertsen L., Lukkonen S. and Sabourin M. (2001): TMP from compressed pine and spruce chips, Int. Mech. Pulp. Conf., Helsinki, Finland, KCL, p. 353

Sabourin M. (1998): Optimizing thermomechanical pulping of southern pine species using a compression pre-treatment, TAPPSA African Pulp Paper Week Conf., Durban, South Africa, p. 341-352

Sabourin M. (2000): Evaluation of a compressive pre-treatment process on TMP properties and energy requirements, Pulp Paper Can., 101(2), p. 50

Sabourin M.J., Vaughn J., Wiseman N., Cort J.B. and Galath P. (2002): Mill Scale Results on TMP Pulping of Southern Pine With Pressurized Chip Pre-treatment, Pulp Paper Can., 103(6), p. 37

Sabourin M. (2003): Methods of reducing energy consumption in thermomechanical pulping, Ph.D. Thesis, University of Manchester, Manchester, England

Sabourin M., Mäentausta O., Räsänen K. and Braeuer P. (2009): Targeting enzyme formulations at selective wood components for optimized thermomechanical pulping of spruce, Int. Mech. Pulp Conf., Sundsvall, Sweden, SPCI, p. 50

Salmén L., Tigerström A. and Fellers C. (1985): Fatigue of wood - characterization of mechanical defibration, J. Pulp Paper Sci., 11(3), p. 68

Salmén L., Dumail J.-F. and Uhmeier A. (1997): Compression behavior of wood in relation to mechanical pulping, Int. Mech. Pulp Conf., Stockholm, Sweden, SPCI, p. 207

Svensson B. (2007): Frictional studies and high strain rate testing of wood under refining conditions", Ph.D. thesis, Mid Sweden University, Sundsvall, Sweden

Tanase M., Stenius P., Johansson L., Hill J. and Sandberg C. (2009): Mass balance of extractives around Impressafiner in mill and pilot scale, Int. Mech. Pulp Conf., Sundsvall, Sweden, SPCI, p. 22

Thornton D.S. and Nunn B.E. (1978): The effect of a plug screw feeder on ether-solubles removal and power reduction during TMP manufacture, Tappi Journal, p. 341

Manuscript received October 1, 2009 Accepted January 8, 2010 